\title{
3D models related to the publication: "Comparative masticatory myology in anteaters and its implications for interpreting morphological convergence in myrmecophagous placentals"
}

\author{
Sérgio Ferreira-Cardoso ${ }^{1 *}$, Pierre-Henri Fabre ${ }^{1,2}$, Benoît de Thoisy ${ }^{3,4}$, Frédéric Delsuc ${ }^{1}$, Lionel Hautier ${ }^{1,2}$ \\ ${ }^{1}$ Institut des Sciences de l'Evolution de Montpellier (ISEM), CNRS, IRD, EPHE, Université de Montpellier, Montpellier, France. \\ ${ }^{2}$ Mammal Section, Life Sciences, Vertebrate Division, The Natural History Museum, London, UK. \\ ${ }^{3}$ Institut Pasteur de la Guyane, Cayenne, French Guiana, France. \\ ${ }^{4}$ Kwata NGO, Cayenne, French Guiana, France. \\ ${ }^{*}$ Corresponding author: sergio.ferreira-cardoso@umontpellier.fr
}

\section{Abstract}

The present 3D Dataset contains the 3D models described in "Comparative masticatory myology in anteaters and its implications for interpreting morphological convergence in myrmecophagous placentals".

Keywords: anteaters, comparative anatomy, convergence, masticatory apparatus, myology, myrmecophagy

Submitted:2020-03-25, published online:2020-07-29. https://doi.org/10.18563/journal.m3.114

$\begin{array}{lll}\text { Inv nr } & \text { Model Id } & \text { Taxon } \\ \text { M1571_JAG } & \text { M3\#522 } & \text { Cyclopes didactylus } \\ \text { M3075_JAG } & \text { M3\#524 } & \text { Tamandua tetradactyla } \\ \text { M3023_JAG } & \text { M3\#523 } & \text { Myrmecophaga tridactyla }\end{array}$

Table 1. 3D surface models of the masticatory, facial-masticatory, and intermandibular musculatures of the pygmy (Cyclopes didactylus), collared (Tamandua tetradactyla), and giant (Myrmecophaga tridactyla) anteaters. All specimens belong to the JAGUARS collection (Kwata NGO, Cayenne, French Guiana).

\section{INTRODUCTION}

South American anteaters (Vermilingua) are one of the mammalian clades that evolved strict myrmecophagy. All three genera present associated morphofunctional features such as tooth loss, reduced masticatory muscles, and the loss of mastication. In the associated manuscript, we perform a comparative description of all three extant anteater genera (Fig. 1 and Table 1), including the first detailed description of the masticatory and intermandibular muscles of the pygmy anteater (Cyclopes didactylus).

\section{METHODS}

The 3D surfaces were manually (muscles) and semi-automatically (skull and mandibles) extracted within AVIZO 9.3 (FEI) using the segmentation threshold and magic wand selection tools. Skull and muscle 3D surfaces were aligned with MeshLab (Cignoni et al., 2008) using reference points. The 3D surface models were tagged and labelled with MorphoDig (Lebrun, 2018). The .ply 3D surfaces can be opened and visualized with a wide range of freeware.

\section{ACKNOWLEDGEMENTS}

S.F.-C., L.H. and F.D. were supported by a European Research Council (ERC) consolidator grant (ConvergeAnt project \#683257). L.H. and F.D. were supported by Centre National de la Recherche Scientifique (CNRS). This work was supported by "Investissements d'Avenir" grants managed by Agence Nationale de la Recherche Labex CEBA (ANR-10-LABX-25-01), Labex CEMEB (ANR-10-LABX-0004), and Labex NUMEV (ANR-10LABX-0020). The MRI platform member of the national infrastructure France-BioImaging is supported by the French National Research Agency (ANR-10-INBS-04, «Investments for the future $\gg$ ). The JAGUARS collection is supported through a FEDER/ERDF grant attributed to Kwata NGO, funded by the European Union, the Collectivité Territoriale de Guyane, and the DEAL Guyane.

\section{BIBLIOGRAPHY}

Cignoni P., Callieri M., Corsini M., Dellepiane M., Ganovelli F., \& Ranzuglia G., 2008. Meshlab: an open-source mesh processing tool. Sixth Eurographics Italian chapter conference, 129-136.

Ferreira-Cardoso S., Fabre P.H., de Thoisy B., Delsuc F., Hautier L., 2020. Comparative masticatory myology in anteaters and its implications for interpreting morphological convergence in myrmecophagous placentals. PeerJ 8:e9690 https://doi.org/10. 7717/peerj.9690

Lebrun R., 2018. MorphoDig, an open-source 3D freeware dedicated to biology. IPC5, Paris, France. 

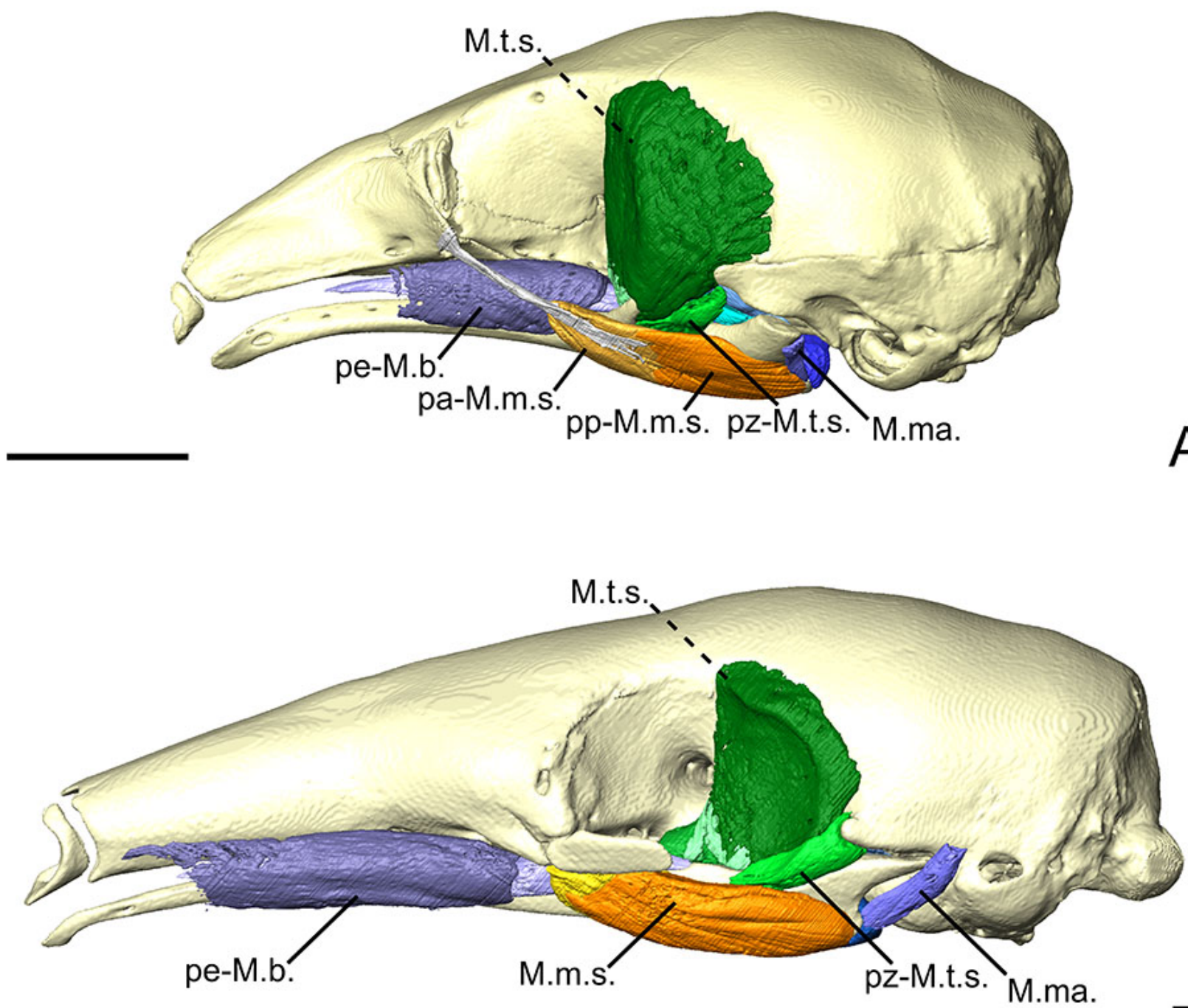

B
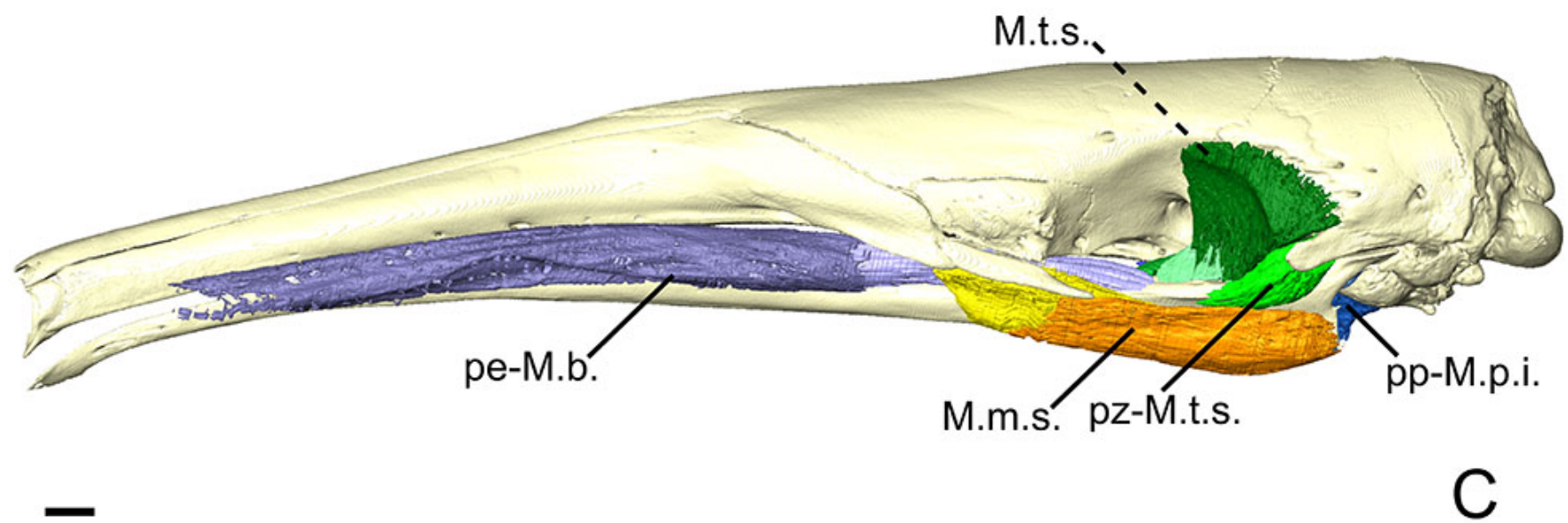

Figure 1. The masticatory and facial-masticatory musculature of Cyclopes didactylus (A), Tamandua tetradactyla (B), and Myrmecophaga tridactyla $(\mathrm{C})$ in lateral view. Scale bar $10 \mathrm{~mm}$. The tendon of the masseter is colored in white. Only the more superficial muscles are labelled. M.ma. - M. mandibuloauricularis; M.m.p. - M. masseter superficialis; pa-M.m.s. - M. masseter superficialis pars anterior; pe-M.b. - M. buccinatorius pars externa; pp-M.m.s. - M. masseter superficialis pars posterior; pp-M.p.i. - M. pterygoideus internus pars posterior; M.t.s. - M. temporalis superficialis; pz-M.t.s. - M. temporalis superficialis pars zygomatica. 